\title{
Epidemiology and Trends in Incidence of Kidney Cancer in Iran
}

\author{
Maryam Mirzaei ${ }^{1}$, Zahra Pournamdar ${ }^{2}$, Hamid Salehiniya ${ }^{1,3,4} *$
}

\begin{abstract}
Background: Kidney cancer has shown an increasing trend in recent decades. This study aimed to determine change in the incidence rate between 2003 and 2009 in Iran. Materials and Methods: In this study, national cancer registry data were used. Crude incidence rates were calculated per 100,000 and age-standardized incidence rates (ASRs) were computed using the direct standardization method and the world standard population. Significant trend of incidence rates was examined by the Cochran-Armitage test for linear trend. Results: A total of 6,944 cases of kidney cancer were reported. The incidence cases increased from 595 patients in 2003 to 1,387 patients in 2009. Sex ratio (male to female) was 1.67. ASR also increased from 1.18 in 2003 to 2.52 in 2009 per 100,000 , but the increasing trend was not significant. Conclusions: A slow increasing trend of incidence rate was observed in the study population. This may be due to an increase of risk factors. It is suggested to perform a study on risk factors for the cancer.
\end{abstract}

Keywords: Kidney cancer - incidence - trend - epidemiology - Iran

Asian Pac J Cancer Prev, 16 (14), 5859-5861

\section{Introduction}

Chronic disease such as cancer is the most common public health problem in the worldwide(Keyghobadi et al., 2015; Razi et al., 2015) Kidney cancer accounts for about 3 percent of all cancers (Ferlay et al., 2015). Renal cell carcinomas are the most common type of kidney tumor, and constitute $80 \%$ of all kidney tumors (Jia et al., 2014).

Based on the report of GLOBOCAN in 2012, 214,000 and 12,400 new cases of the cancer occur in men and women, respectively. This cancer is considered ninth and fourteenth common cancer in males and females, respectively. It is the sixteenth cause of cancer death in the world (Ferlay et al., 2015). Kidney cancer is one of the most common cancers in Western countries (Gunes et al., 2012). Incidence rate of the cancer is lower in African and Southeast Asian countries than eastern and northern Europe, Australia and North America (Ferlay et al.; Singam et al., 2010).

In recent years, an increasing trend was observed in the incidence and mortality rates worldwide, especially in most developed countries (Chow et al., 2010; Tan et al., 2015). This cancer is one of the public health problems in United States (U.S), where increased incidence of this cancer has been reported in different ethnic groups ( $\mathrm{Li}$ et al., 2014).

It is considered the eighth rank of all cancers and the twelfth leading cause of death from cancer in Canada (De et al., 2014).

Differences in cancer incidence and mortality rates in different regions of the world could indicate the role of various risk factors and genetic differences in the etiology of this cancer. The most important risk factors for the cancer include smoking, obesity, diabetes mellitus, insufficient physical activity, and blood pressure (Chow et al., 2010; Basiri et al., 2014; Washio et al., 2014b). An increase in the incidence of kidney cancer has been reported in various parts of the world (Levi et al., 2008; Chow et al., 2010; De et al., 2014). No epidemiological study has been carried out on the trend of this type of cancer in Iran. An increase or decrease in the cancer rate over time emphasizes the need to examine its trends for better planning. This study aimed to determine the trend of the cancer incidence rate between 2003 and 2009 in Iran.

\section{Materials and Methods}

This study was carried out based on existing data, obtained from the national report on cancer registry and disease management center of ministry of health in Ira. The existing data contained data from 41 pathology centers of medical university in the country between 2003 and 2009. All registered cases were studied by each province. The incidence rate was calculated as per 100,000 people and ASR using direct standardization and the standard population of World Health Organization (W.H.O). The

${ }^{1}$ Department of Epidemiology and Biostatistics, School of Public Health, Tabriz University of Medical Sciences, Tabriz, ${ }^{2}$ Pregnancy Health Research Center, Zahedan University Of Medical Sciences, Zahedan, ${ }^{3}$ Minimally Invasive Surgery Research Center, Iran University of Medical Sciences, ${ }^{4}$ Department of Epidemiology and Biostatistics, school of public health, Tehran University of medical sciences, Tehran, Iran *For correspondence: alesaleh70@yahoo.com 
data collected is encoding using ICD-O, which related to the code $\mathrm{C}$ 64-66. The number of cases, and crude and standardized incidence rates was also examined by sex and each province. Data was analyzed using Cochran Armitage test for linear trend and software of WinPepi 2.1.

\section{Results}

In our study, a total of 6944 cases of kidney cancer were diagnosed since the beginning of 2003 until the end of 2009 . Of the patients, 4352 cases were men $(1.86 \%)$ and 2592 women $(1.42 \%)$. The highest number of cases was detected in both sexes in 2009 . The sex ratio in the population studied was 1.67 . Table1 shows the distribution of patients with kidney cancer according to the years when the disease has been diagnosed. The incidence of kidney cancer during the years studied had a slow increasing trend in both sexes (Figure 1).

There was a difference in standardized incidence

Table 1. The Incidence and Frequency of Kidney Cancer, 2003-2009

\begin{tabular}{cccccccc}
\hline & $\mathrm{N}(\%)$ & $\mathrm{N}(\%)$ & \multicolumn{2}{c}{$\mathrm{CIR}$} & \multicolumn{2}{c}{ ASR } & $\mathrm{M}: \mathrm{F}$ \\
Years & $\mathrm{F}$ & $\mathrm{M}$ & $\mathrm{F}$ & $\mathrm{M}$ & $\mathrm{F}$ & $\mathrm{M}$ & \\
\hline 2003 & $228(1.35)$ & $367(1.70)$ & 0.70 & 1.08 & 0.96 & 1.39 & 1.45 \\
2004 & $260(1.27)$ & $453(1.69)$ & 0.79 & 1.31 & 1.10 & 1.76 & 1.60 \\
2005 & $334(1.36)$ & $569(1 . .81)$ & 0.97 & 1.57 & 1.39 & 2.08 & 1.50 \\
2006 & $395(1.52)$ & $646(1.91)$ & 1.16 & 1.79 & 1.58 & 2.35 & 1.49 \\
2007 & $413(1.51)$ & $669(1.93)$ & 1.21 & 1.86 & 1.64 & 2.43 & 1.48 \\
2008 & $444(1.31)$ & $779(1.84)$ & 1.30 & 2.16 & 1.81 & 2.93 & 1.62 \\
2009 & $518(1.57)$ & $869(2.11)$ & 1.51 & 2.21 & 2.05 & 2.99 & 1.68 \\
\hline Total & $2592(1.42)$ & $4352(1.86)$ & 8.14 & 11.89 & 10.41 & 15.8 & 1.67 \\
\hline
\end{tabular}

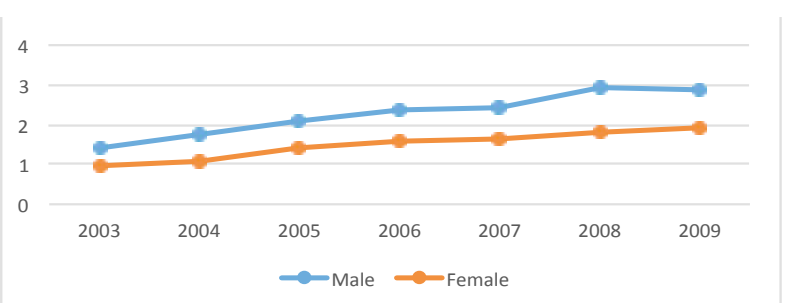

in these years. The rate increased from 0.96 in 2003 to 2.05 in 2009 in women, and from 1.39 in 2003 to 2.99 in 2009 in men. Table 2 summarizes ASR of kidney cancer between 2005 and 2009. The ASR was higher in men than women in all age groups. It was also high in the older age groups, so that age group of 80-84 years has the highest ASR in both sexes.

The incidence rate of kidney cancer in both sexes at 30 provinces is shown that highest incidence rate was observed in the provinces of Fars, Tehran, Khuzestan, and Chahar-Mahal Bakhtiari.

\section{Discussion}

Our findings showed that a slow increasing trend of the cancer incidence during years of the study. The incidence rate of the cancer was also higher in men than women. ASRs of the cancer were 1.18, 1.43, 1.74, 1.97, 2.04,2.37, and 2.4 between 2003 and 2009 .

A series of different environmental and genetic factors are effective in the incidence of cancer. If one factor is considered, it is not obviously explain an increase or decrease of the cancer. The increase of this cancer may be due to changes in the pattern of cancer risk factors. Improving the cancer registration system in the country was also another reason for the increase.

Other studies also indicated that the incidence cancer trend was higher in developed countries than developing and less developed countries, as Iran (Chow et al., 2010). In a study performed in United States, it was found that one of the reasons for the increase of cancer is raising aging population (Wallen et al., 2007).

The incidence trend of the cancer is different according to age, race, and various regions of the world. Global reports suggest that kidney cancer is associated with an increasing trend in most developed countries (Znaor et al., 2014).

The cancer incidence rate is different in various regions of the world because of different prevalence of

Table 2. The ASR of Kidney Cancer by Sex and Age Group, between 2005 and 2009

\begin{tabular}{|c|c|c|c|c|c|c|c|c|c|c|}
\hline \multirow[b]{2}{*}{ Age group } & \multicolumn{2}{|c|}{2004} & \multicolumn{2}{|c|}{2005} & \multicolumn{2}{|c|}{2006} & \multicolumn{2}{|c|}{2007} & \multicolumn{2}{|c|}{2008} \\
\hline & $\mathrm{F}$ & $\mathrm{M}$ & $\mathrm{F}$ & M & $\mathrm{F}$ & $\mathrm{M}$ & $\mathrm{F}$ & $\mathrm{M}$ & $\mathrm{F}$ & M \\
\hline $0-4$ & 0.88 & 0.67 & 0.92 & 1.08 & 1.17 & 0.57 & 0.77 & 1.04 & 1.03 & 1.07 \\
\hline 9-May & 0.22 & 0.26 & 0.36 & 0.34 & 0.27 & 0.52 & 0.27 & 0.31 & 0.41 & 0.32 \\
\hline 14-Oct & 0.02 & 0.02 & 0.13 & 0.1 & 0.07 & 0.02 & 0.15 & 0.08 & 0 & 0.08 \\
\hline $15-19$ & 0.02 & 0.02 & 0.06 & 0.04 & 0.1 & 0.08 & 0.1 & 0.08 & 0.11 & 0 \\
\hline $20-24$ & 0.03 & 0.12 & 0.11 & 0.18 & 0.14 & 0.21 & 0.2 & 0.12 & 0.11 & 0.12 \\
\hline $25-29$ & 0.22 & 0.1 & 0.33 & 0.23 & 0.48 & 0.2 & 0.32 & 0.27 & 0.34 & 0.2 \\
\hline $30-34$ & 0.32 & 0.24 & 0.24 & 0.49 & 0.69 & 0.69 & 0.73 & 0.69 & 0.82 & 0.61 \\
\hline $35-39$ & 0.67 & 0.88 & 1.45 & 0.88 & 0.82 & 1.91 & 0.82 & 0.88 & 0.67 & 1.01 \\
\hline $40-44$ & 1.22 & 2.1 & 1.49 & 2.28 & 1.91 & 2.06 & 1.75 & 2.76 & 2.01 & 2.63 \\
\hline $45-49$ & 2.23 & 3 & 2.31 & 4.77 & 3.17 & 3.58 & 3.1 & 5.15 & 2.62 & 3.92 \\
\hline $50-54$ & 3.79 & 8.07 & 4.37 & 9.7 & 3.89 & 8.84 & 3.16 & 10.23 & 6.43 & 7.45 \\
\hline $55-59$ & 3.88 & 6.34 & 5.35 & 7.06 & 5.84 & 8.8 & 45.96 & 12.04 & 7.31 & 9.98 \\
\hline $60-64$ & 6.2 & 7.18 & 5.92 & 6.29 & 6.07 & 7.91 & 7.89 & 9.94 & 7.25 & 14.69 \\
\hline $65-69$ & 6.53 & 7.35 & 6.05 & 7.03 & 4.54 & 7.62 & 6.22 & 7.62 & 7.55 & 14.04 \\
\hline $70-74$ & 5.78 & 11.19 & 5.8 & 10.55 & 5.8 & 12.76 & 9.09 & 12.93 & 8.16 & 12.63 \\
\hline $75-79$ & 4.58 & 8.66 & 3.29 & 9.86 & 6.57 & 9.4 & 7.23 & 12.21 & 11.59 & 12.71 \\
\hline $80-84$ & 3.6 & 19.31 & 9.03 & 13.85 & 3.61 & 13.85 & 9.93 & 23.54 & 7.95 & 17.84 \\
\hline $85+$ & 1 & 1.85 & 2.02 & 6.5 & 1.01 & 3.71 & 5.04 & 8.36 & 3.76 & 7.88 \\
\hline
\end{tabular}


risk factors for this type of cancer, including obesity, hypertension, smoking and insufficient physical activity, and exposure to occupational carcinogens (Wilson et al., 2008a; Li et al., 2014; Washio et al., 2014a; 2014b). Obesity alone is responsible for $25 \%$ of the cancer (Wilson et al., 2008b). Based on the third report of the statues of non-communicable disease risk factors, the prevalence of obesity and hypertension in Iran was estimated about 22.3 and 26.6\%, respectively (Esteghamati et al., 2009).

In United States, about 40 percent of all cancers are attributed to obesity and overweight (Moore et al., 2005). Our study revealed that there was an increase in age groups of 70-74 years and 80-84 years. In other words, as age increases, incidence of the cancer also increases, similar to findings from other studies (Nepple et al., 2012). Based on survey in Iran , the difference of age distribution in both sexes was not statistically significant (Basiri et al., 2014).

In this study, sex ratio was 167 . It means that there are 167 men for every 100 women. In a study in Australia, the ratio was 2 to 1 (Luke et al., 2011), and according to study in Lebanon, repotting that $75 \%$ of the patients having kidney cancer are men (Khafaja et al., 2015). It seems that Iranian men more expose to risk factors of the cancer than Iranian women. This can lead to a lower incidence of the cancer in these women.

There were differences in the incidence rate of the cancer in various regions of Iran. This may be due to differences in the distribution of the prevalence of risk factors associated with this type of cancer such as exposure to various industrial chemical materials in industrial cities.

In conclusion, although the incidence of kidney cancer in Iranian population is lower than developed countries, the trend in the incidence of kidney cancer is rising. The increase is attributed to improvement of national cancer registry and changes in risk factors of the cancer. Therefore, it is essential to carry out Etiology studies.

\section{References}

Basiri A, Shakhssalim N, Jalaly NY, et al (2014). Difference in the Incidences of the Most Prevalent Urologic Cancers from 2003 to 2009 in Iran. Asian Pac J Cancer Prev, 15, 1459-63.

Chow WH, Dong LM, Devesa SS (2010). Epidemiology and risk factors for kidney cancer. Nat Rev Urol, 7, 245-57.

De P, Otterstatter MC, Semenciw R, et al (2014). Trends in incidence, mortality, and survival for kidney cancer in Canada, 1986-2007. Cancer Causes Control, 25, 1271-81.

Esteghamati A, Meysamie A, Khalilzadeh O, et al (2009). Third national Surveillance of Risk Factors of Non-Communicable Diseases (SuRFNCD-2007) in Iran: methods and results on prevalence of diabetes, hypertension, obesity, central obesity, and dyslipidemia. BMC Public Health, 9, 167.

Ferlay J, Soerjomataram I, Dikshit R, et al (2015). Cancer incidence and mortality worldwide: sources, methods and major patterns in GLOBOCAN 2012. International Journal of Cancer, 136, 359-86.

Ferlay J, Soerjomataram I, Ervik M, et al (2014). Cancer incidence and mortality worldwide: IARC CancerBase No. 11 [Internet]. Lyon, France: International Agency for Research on Cancer [Online]. Available from: http:// globocan.iarc.fr.

Gunes M, Gecit I, Pirincci N, et al (2012). Nature of Lesions
DOI:http://dx.doi.org/10.7314/APJCP.2015.16.14.5859

Epidemiology and Trends in Incidence of Kidney Cancer in Iran

Undergoing Radical Nephrectomy for Renal Cancer. Asian Pac J Cancer Prev, 13, 4431-3.

Jia H-Y, Liu J-L, Zhou C-J, et al (2014). High expression of MICA in human kidney cancer tissue and renal cell carcinoma lines. Asian Pac J Cancer Prev, 15, 1715-7.

Keyghobadi N, Rafiemanesh H, Mohammadian-Hafshejani A, et al (2015). Epidemiology and trend of cancers in the province of Kerman: southeast of Iran. Asian Pac J Cancer Prev, 16, 1409-13.

Khafaja S, Kourie HR, Matar D, et al (2015). Kidney Cancer in Lebanon: a Specific Histological Distribution? Asian Pac J Cancer Prev, 16, 363-5.

Levi F, Ferlay J, Galeone C, et al (2008). The changing pattern of kidney cancer incidence and mortality in Europe. $B J U$ Int , 101, 949-58.

Li J, Weir HK, Jim MA, et al (2014). Kidney cancer incidence and mortality among American Indians and Alaska Natives in the United States, 1990-2009. Am J Public Health, 104, 396-403.

Luke C, Sargent N, Pittman K, et al (2011). Epidemiology of cancers of the kidney in an Australian population. Asian Pac J Cancer Prev, 12, 2893-9.

Moore LE, Wilson RT, Campleman SL (2005). Lifestyle factors, exposures, genetic susceptibility, and renal cell cancer risk: a review. Cancer Investigation, 23, 240-55.

Nepple KG, Yang L, Grubb RL, et al (2012). Population based analysis of the increasing incidence of kidney cancer in the United States: evaluation of age specific trends from 1975 to 2006. J Urol, 187, 32-8.

Razi S, Rafiemanesh H, Ghoncheh M, et al (2015). Changing Trends of Types of Skin Cancer in Iran. Asian Pac J Cancer Prev, 16, 4955-8.

Singam P, Ho C, Hong GE, et al (2010). Clinical characteristics of renal cancer in Malaysia: A ten year review. Asian Pac J Cancer Prev, 11, 503-6.

Tan H-J, Filson CP, Litwin MS (2015). Contemporary, age-based trends in the incidence and management of patients with early-stage kidney cancer. Urologic Oncology: Seminars and Original Investigations, Elsevier, 21, 19-21.

Wallen EM, Pruthi RS, Joyce GF, et al (2007). Kidney cancer. J Urology, 177, 2006-19.

Washio M, Mori M, Mikami K, et al (2014a). Risk factors for renal cell carcinoma in a Japanese population. Asian Pac J Cancer Prev, 15, 9065-70.

Washio M, Mori M, Mikami K, et al (2014b). Cigarette smoking and other risk factors for kidney cancer death in a Japanese population: japan collaborative cohort study for evaluation of cancer risk (JACC study). Asian Pac J Cancer Prev, 14, 6523-8.

Wilson RT, Donahue M, Gridley G, et al (2008a). Shared occupational risks for transitional cell cancer of the bladder and renal pelvis among men and women in Sweden. American J Industrial Medicine, 51, 83-99.

Wilson RT, Richardson LC, Kelly JJ, et al (2008b). Cancers of the urinary tract among American Indians and Alaska Natives in the United States, 1999-2004. Cancer, 113, 1213-24.

Znaor A, Lortet-Tieulent J, Laversanne M, et al (2014). International variations and trends in renal cell carcinoma incidence and mortality. European urology. 